\title{
The epidemiological situation in south east asia
}

\section{T ITO}

Department of Leprology, Research Institute for Microbial Diseases Osaka University, 3-1, Yamadaoka, Suita, Osaka, Japan

\section{The Epidemiological Situation in Japan except Okinawa}

National leprosy control programme in Japan started in 1907 with the principle of segregation. The estimated number of leprosy patients in that year was over 23,000 and prevalence rate was estimated to be 0.5 per 1,000. Table 1 shows the prevalence of leprosy in Japan except Okinawa. Number of registered patients declined clearly before 1940, and then became stationary for two decades, but after 1960 the number has been declining again.

\section{TABLE 1}

Number of registered patients in Japan except Okinawa

\begin{tabular}{ccc}
\hline Year & No.of Patients & $\begin{array}{l}\text { Prevalence Rate } \\
\text { per } 1.000\end{array}$ \\
\hline 1925 & 15,351 & 0.26 \\
1930 & 14,261 & 0.23 \\
1940 & 11,326 & 0.15 \\
1950 & 11,094 & 0.13 \\
1960 & 11,565 & 0.12 \\
1970 & 9,565 & 0.09 \\
1980 & 7,977 & 0.07 \\
\hline
\end{tabular}

The stationary stage in numbers of patients from 1940 to 1960 may be caused not only by the influence of the IInd World War, but also by the improvement of nutrition and medical services in 
Japanese leprosy hospitals. On the other hanh, prevalence rate of leprosy has been declining smoothly and clearly. Furthermore, number of active cases in 1980 was less than 2,800, so it is strogly suggested that Japan will be able to eradicate leprosy in the early era of the next century.

Fig. 1 shows the number of newly registered leprosy patients in Japan except Okinawa. The peak is seen in 1949, and three stages are noticeable, namel rapidly declining stage from 1949 to 1952, stationary stage from 1953 to 1959, and slowly but regularly declining stage since 1960. This figure shows a remakable tendency for decline in frequency of the disease.

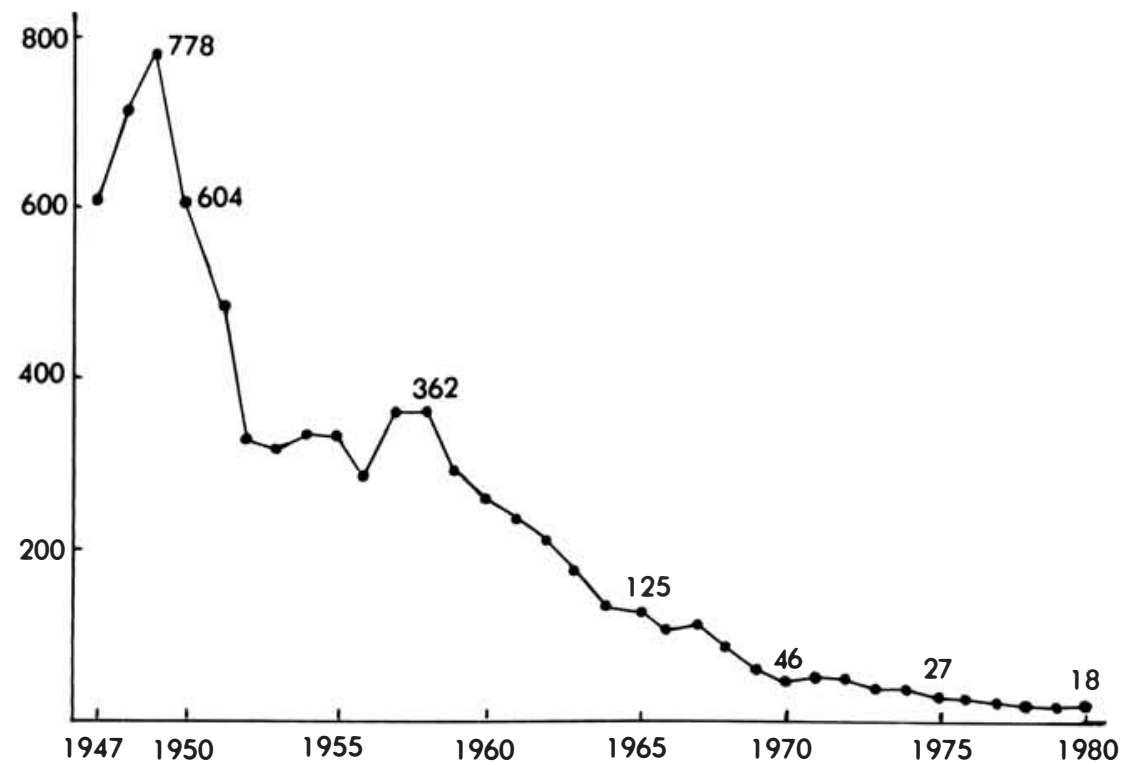

Fig. 1. Number of newly registered leprosy patients in Japan except Okinawa.

Table 2 shows the five years' cumulative number of newly registered patients from 1950 to 1979. The result also shows a regularly declining tendency of the disease. It can be concluded that leprosy has declined markedly in Japan except Okinawa during the later decades.

Fig. 2 shows the correlationship between newly registered number of leprosy and tuberculosis. There is a high correlation between frequency of leprosy and tuberculosis witl the correlation coefficient of 0.98 .

Fig. 3 shows the age distribution of the patients. Significant increase of old cases more than 69 years old, and significant decrease of young cases less than 30 years old can be noticeable in the patients found after 1975 compared with the patients detected from 1956 to 1962. This phenomenon is also supporting a declining tevdency of the disease. 


\section{TABLE 2}

Five years' cumulative number of newly registered leprosy patients in Japan except Okinawa

\begin{tabular}{cc}
\hline Years & NO. of patients \\
\hline $1950-1954$ & 2,065 \\
$1955-1959$ & 1,632 \\
$1960-1964$ & 1,013 \\
$1965-1969$ & 494 \\
$1970-1979$ & 221 \\
$1975-110$
\end{tabular}

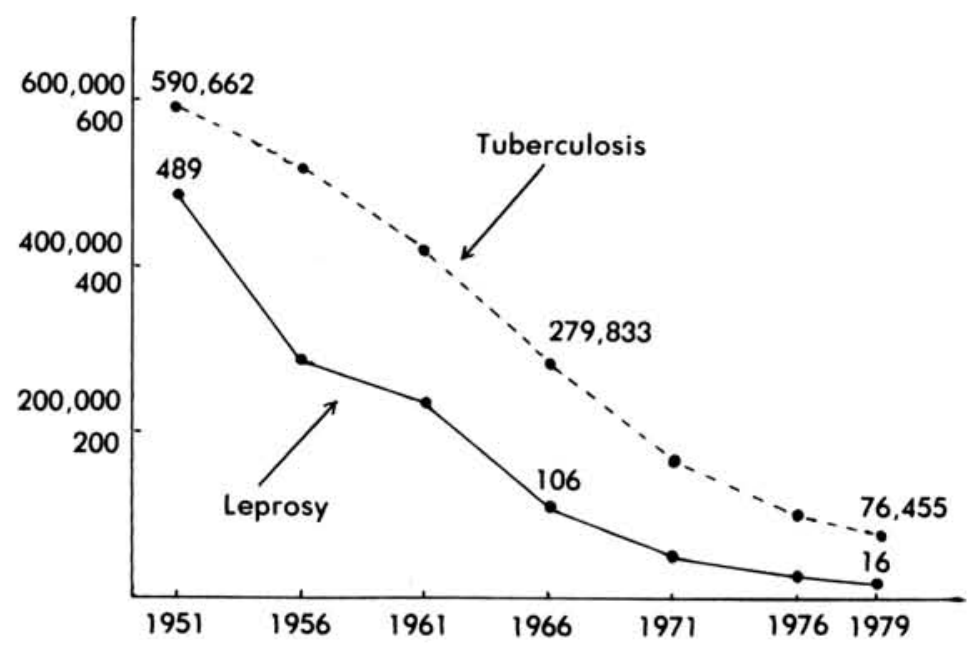

Fig. 2. Number of newly registered patients of leprosy and tuberculosis in Japan except Okinawa. Number of tuberculosis patients after 1972 included Okinawa's patients.

Fig. 4 shows the type prevalence of leprosy. Slight decrease of $\mathrm{T}$ type and slight increase of $\mathrm{B}+\mathrm{L}$ group are noticeable in the patients found after 1974, but these differences are not significant. The problem is the fact that more than $70 \%$ of the patients who were detected after 1974 had multi-bacillary type of leprosy. Early diagnosis and early treatment of leprosy are still strongly requested in Japan. 


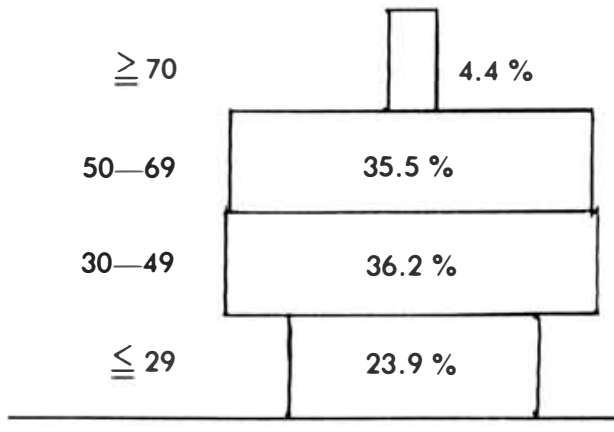

newly detected during

$1956-1962$

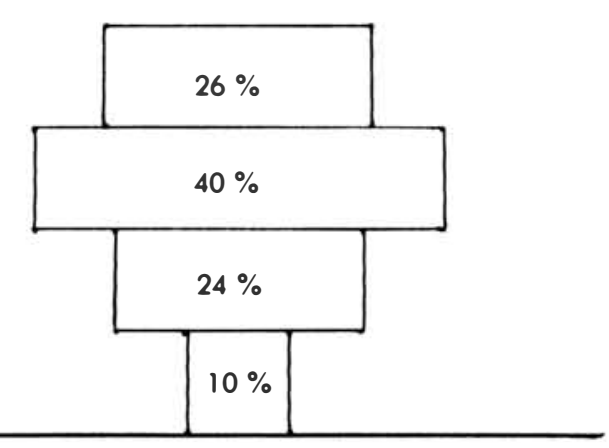

Newly detected during

$1975-1980$

Fig. 3. Age distribution of leprosy patients in Japan except Okinawa.

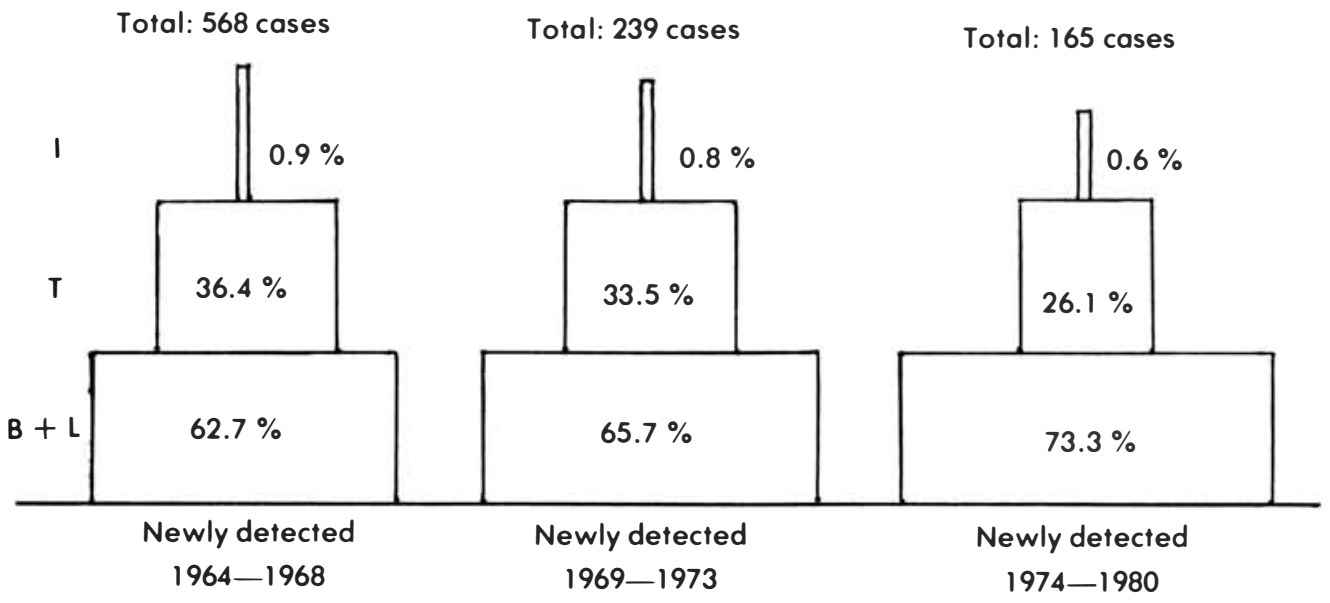

Fig. 4. Type prevalence of leprosy patients in Japan except Okinawa.

The Epidemiological Situation in Thailand

Leprosy was highly prevalent in the northeastern and northern part of Thailand, and prevalence rate was estimated to be 5 per 1,000 in 1953 from the results of random sampling survey carried out by WHO, so that the total number of the patients was estimated to be about 14,000. The goverment leprosy control programme started in 1955 and now its activities are covering whole country, then up to 1979110,303 cases were detected, and 63,653 cases have been released from control after following the criteria stipulated by WHO. The total number of patients under treatment in 1979 was 45,635. Prevalence rate has been gradually declining to less than 1 per 1,000 in 1976 and 0.86 per 1,000 in 1979. Leprosy control activities in Thailand should be highly evaluated by these excell- 
ent results.

On the other hand, number of newly detected cases in the last decade is not showing clear declining tedency of the disease as shown in Fig. 5. There is a tedency of increasing in number of newly detected cases, but this phenomenon must be due to the efforts of intensive case finding, and as a matter of fact the goverment of Thailand made great efforts to strengthen the case finding activitity of leprosy in the last decade, so that it can be concluded that the frequency of the disease is not increasing in Thailand. Correlationship between leprosy and tuberculosis could not be analysed because of limitted information of tuberculosis.

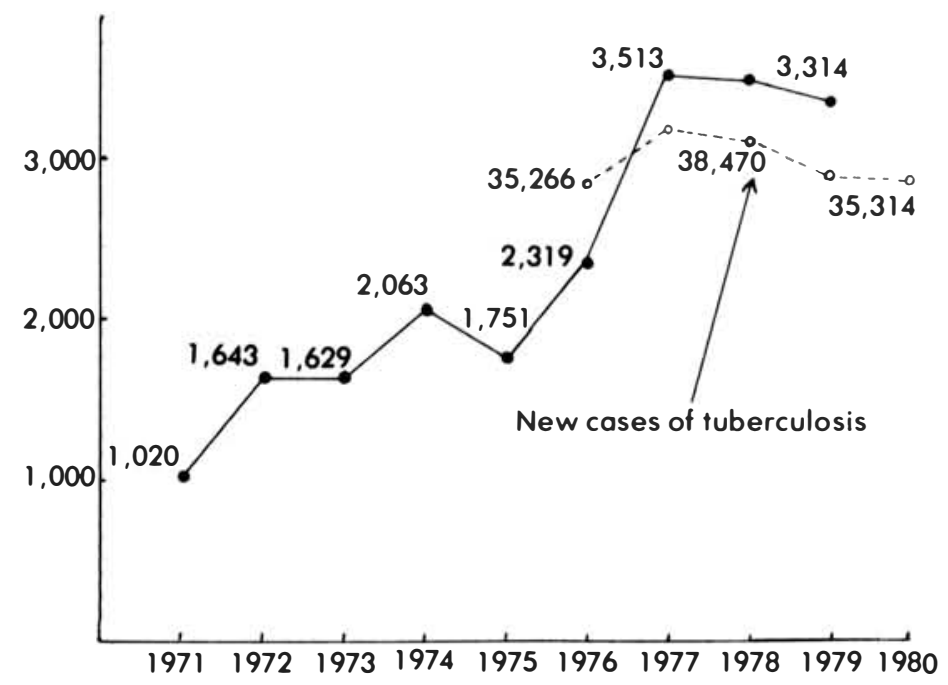

Fig. 5. Number of newly detected leprosy patients in Thailand

Fig. 6 shows the age distribution of newly detected leprosy patients in Thailand. The peak of age distribution curve is seen in the middle age group from 35 to 44 years old, and the rate of young group of less than 15 years old is only less than 13\%. This pattern may be an early sign of decline of leprosy, and the clear decline of the disease in the following decade may be expected with high possibility.

Fig. 7 shows the type prevalence of leprosy in Thailand. Type ratio of $\mathrm{L}$ and $\mathrm{B}$ in newly detected cases during October 1970 to September 1980 is significantly different from the ratio in all cases on March 31, 1981. This phenomenon must be due to the accumulation of lepromatous patients in the registration. 


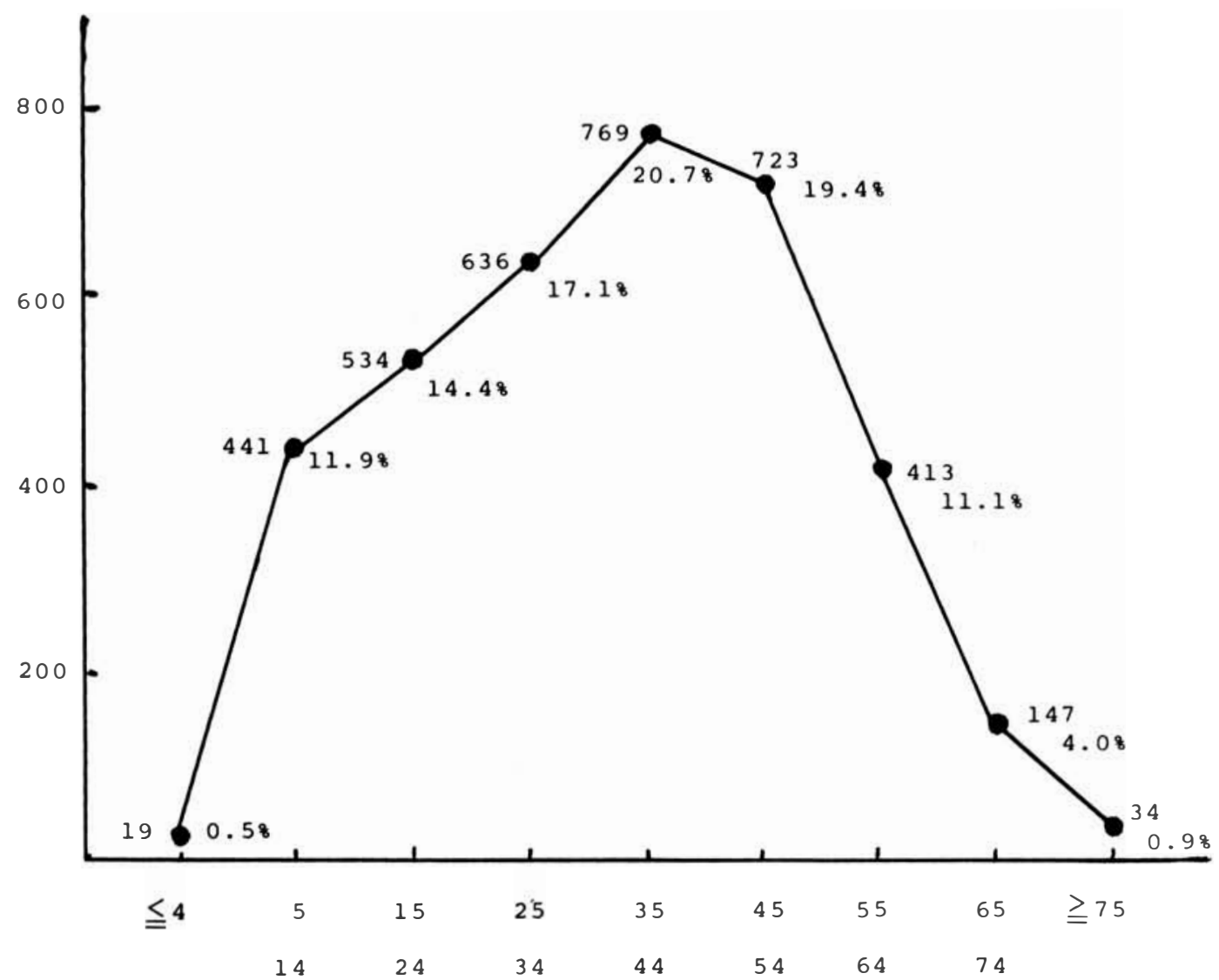

Fig. 6. Age distribution of newly detected leprosy patients in Thailand during Oct.1, 1979 to Sept. 30, 1980

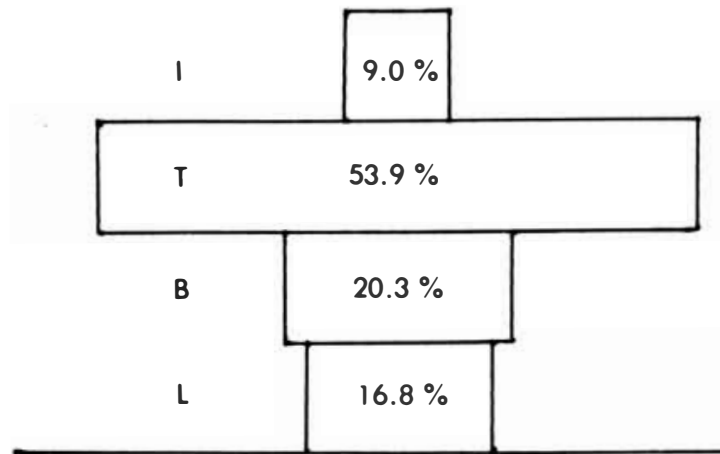

New cases found furing

Oct. 1, 1979 - Sept. 30, 1980

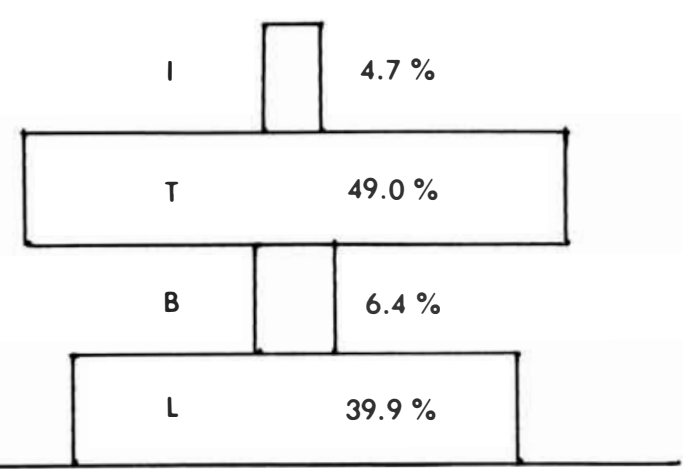

All cases on March 31, 1981

Fig. 7. Type prevalence of leprosy in Thailand 


\section{The Epidemiological Situation in the Philippines}

National leprosy control programme of the Philippines started in 1955, and now its activities are covering whole country. Fig. 8 shows the prevalence of leprosy in the Philippines. The number of active cases has been increasing gradually, but prevalence rate seems to be in the stationary stage since 1970. No more significant increase of prevalence rate in the following decades may be expected by this figure.

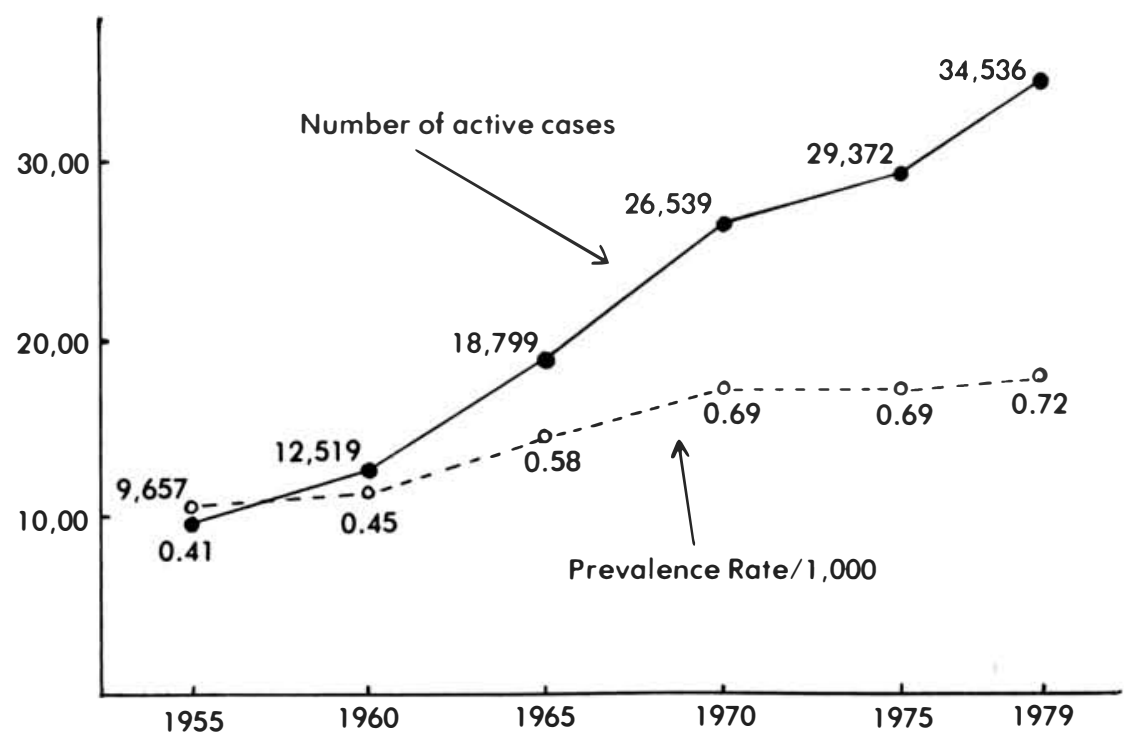

Fig. 8. Prevalence rate of leprosy in the Philippines per 1,000

Fig. 9 shows the number of newly detected cases in the Philippines. Since 1960, there is no significant change in number of newly detected cases, but case detection rate rate has been declining gradually and regurally. This phenomenon may be an early sign of decline of the disease, and clear decline of leprosy in the following decades may be expected by this figure. Correlationship between leprosy and tuberculosis could not be analysed because of limitted information of tuberculosis.

Fig. 10 shows the type prevalence of leprosy in the Philippines. There is no change of type prevalence since 1965, and the ratio of $\mathrm{L}+\mathrm{B}$ is almost similar to $\mathrm{L}+\mathrm{B}$ ratio in Thailand, but significantly lower than L + B ratio in Japan. The Philippines and Thailand are showing tropical type prevalence of leprosy. 


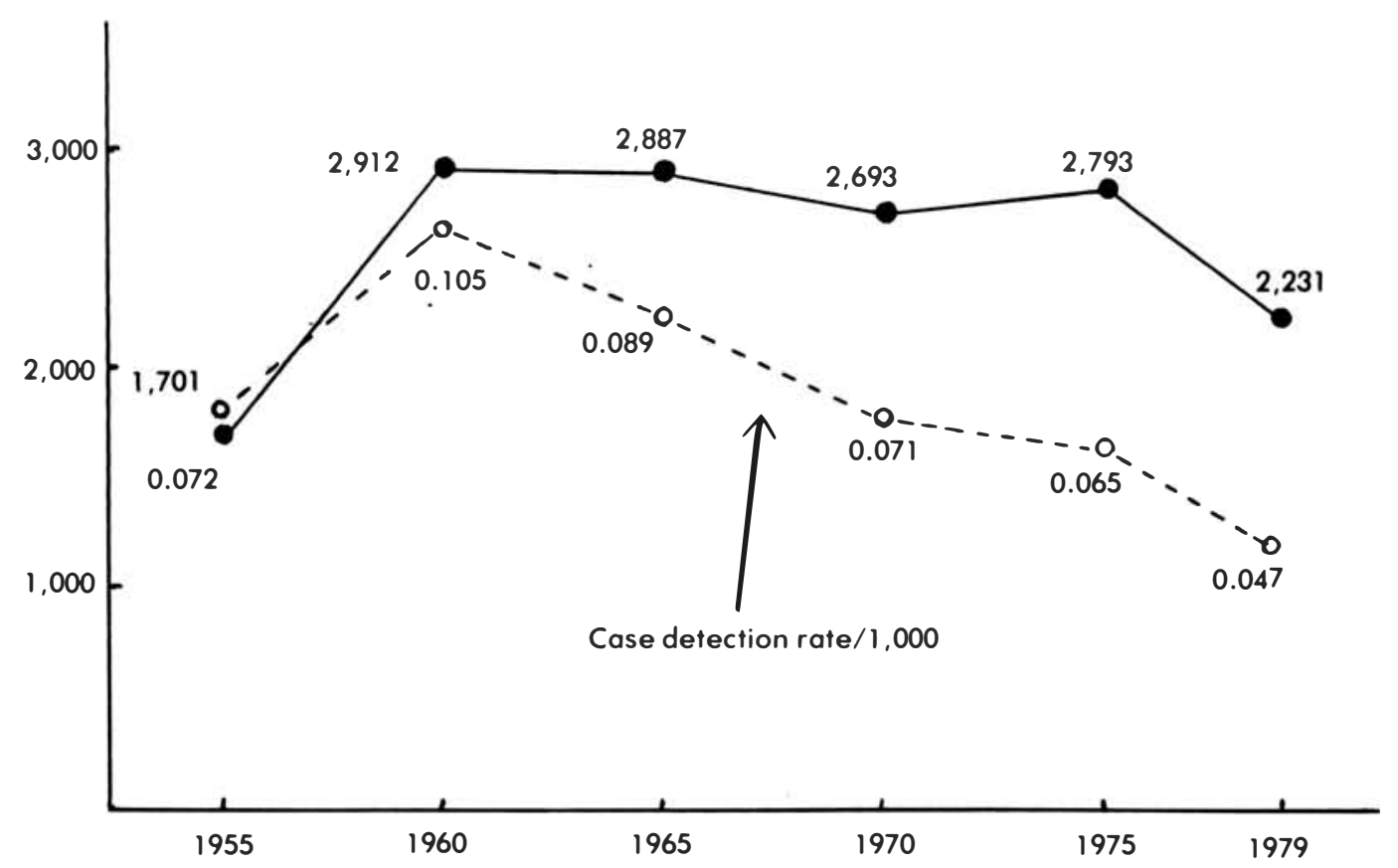

Fig. 9. Number of newly detected leprosy patients in the Philippines.

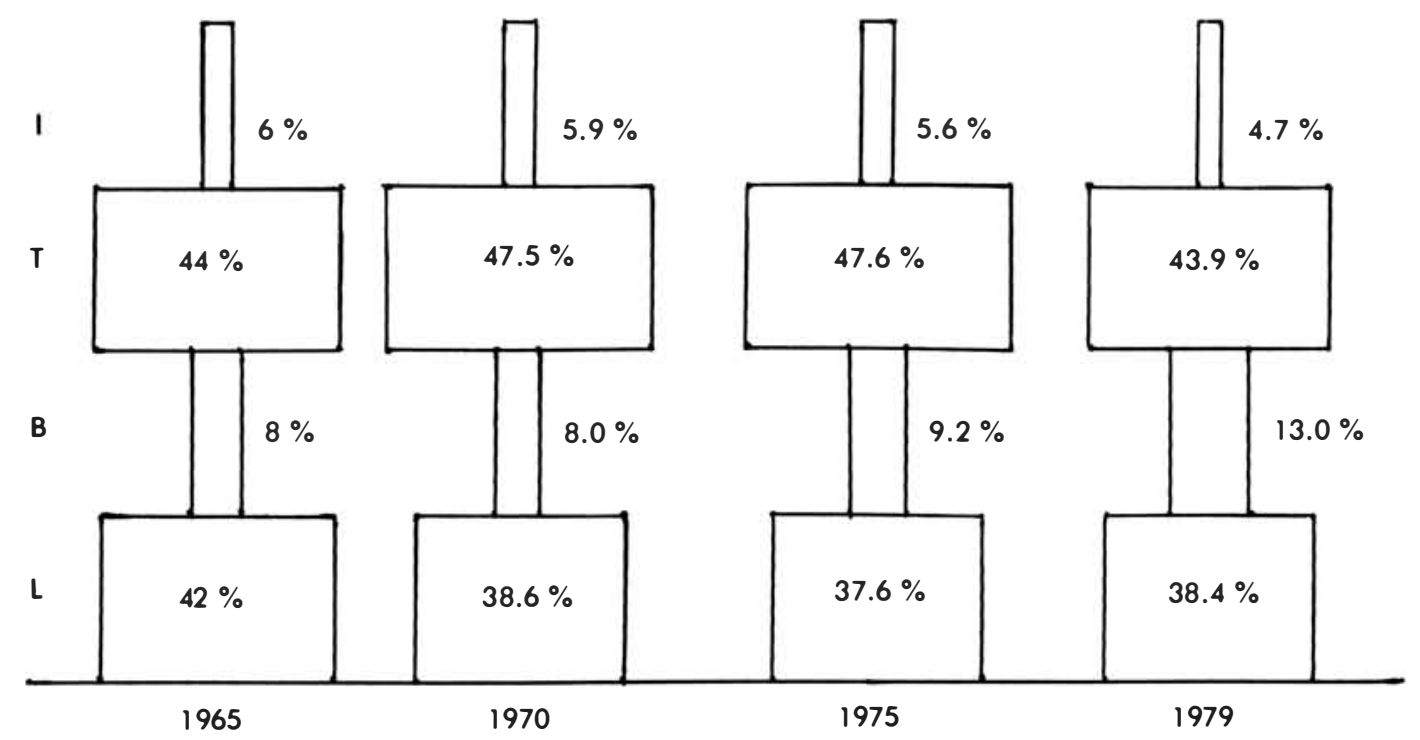

Fig. 10. Type prevalence of leprosy in the Philippines.

\section{Aknowledgements}

The author is very much grateful for the kind cooperation of

Dr. Teera Ramasoot, Director of Leprosy Division, Department of 
Communicable Disease Control, Ministry of Public Health, Thailand, and of Dr. Fernand A. Jose, JR., Head of Leprosy Control Service, Bureau of Health Services, Ministry of Health, Republic of the Philippines in providing statistical data of respective country and permiting to use their previous reports. 